\title{
The Credibility Question: Challenge or Opportunity?
}

Kristin Forner, $\mathrm{MD}^{1,2, *}$

The ACGME Common Program Requirements mandate that all surgical training programs provide education in ethical issues specific to the surgical arena. Programs are also responsible both for enhancing the likelihood that residents find meaning in their work and for creating systems that help them manage more challenging cases. In the spring of 2019, experts in the fields of palliative medicine (Kristin Forner, $\mathrm{MD}$ ), bioethics (Katherine Meacham, $\mathrm{PhD}$ ), and resiliency (Stephanie Citron, $\mathrm{PhD}$ ), with the support of the Mountain Area Health Education Center and the Surgery Department at Mission Hospital in Asheville, North Carolina, developed a curriculum to meet these requirements for PGY 1 and PGY 2 general surgery residents. ${ }^{1}$ The motivation of the curriculum was to address the areas within surgical training where all three fields overlap.

Using Ethical Issues in Surgical Care (Ferreres, $2017)^{2}$ as the textual guide, the three course directors created a year-long curriculum consisting of 6 twohour sessions. Dinner was provided at each session, and the directors facilitated a mixed didactic/discussion format with a brief reflective writing exercise at the conclusion of each session. The six sessions focused on three core bioethical and palliative medicine-related topics: informed consent, adverse events, and end-oflife care.

The first three sessions were attended by all PGY 1 and PGY 2 residents, and were facilitated by the course directors. Surgical faculty members were not allowed to attend, as the course directors assumed that residents would be reluctant to express them- selves freely in the presence of surgery faculty. However, after the first three sessions where the course directors noted that resident participation was both minimal and superficial, three surgical faculty members were invited to attend each of the last three sessions. These surgical faculty members' support resulted in dramatically more powerful sessions, in large part because they now held critical, but heretofore missing, credibility. The credibility that came with the surgical faculty involvement (1) allowed for more authentic and meaningful reflections on emotionally charged patient and colleague encounters and technically challenging surgical scenarios and (2) provided accountability when residents drew misguided conclusions or denied the impact of these cases on their individual psyches.

Qualitative outcomes from this curriculum showed that an ethics curriculum can be successfully integrated into a surgical training program. Efficacy is improved, however, if there is involvement of both content experts and surgical faculty. Evidence also showed that the chosen topics provided education in palliative medicine. Given the addition of faculty for the last three sessions, the impact of providing this education was larger and more influential than expected. Surveys of both residents and faculty demonstrated improvement in knowledge of ethical and resiliency issues, as well as the differences between hospice and palliative medicine, and when it may be appropriate to call for a palliative medicine consult.

It is unclear whether such a curriculum will improve resident well-being. By understanding the ethical issues

\footnotetext{
Department of Internal Medicine, University of North Carolina, North Carolina, USA.

${ }^{2}$ Department of Palliative Medicine, Mission Hospital, Asheville, North Carolina, USA.

*Address correspondence to: Kristin Forner, MD, Department of Palliative Care, Mission Hospital, 509 Biltmore Avenue, Asheville, NC 28801, USA, E-mail: doctorkiki@yahoo.com
}

(C) Kristin Forner, 2020; Published by Mary Ann Liebert, Inc. This Open Access article is distributed under the terms of the Creative Commons License (http://creativecommons.org/licenses/by/4.0), which permits unrestricted use, distribution, and reproduction in any medium, provided the original work is properly cited. 
Table 1. Outline of Hospital Ethics and Resiliency Integrated Training (HEAR-IT) Curriculum

\begin{tabular}{|c|c|c|c|c|}
\hline & Topic & Knowledge & Skills & Disposition \\
\hline Session 1 & Informed consent & Shared decision making & Best case/worst case & Empathy \\
\hline Session 2 & & $\begin{array}{l}\text { Obligation to refuse to perform } \\
\text { treatments that are harmful }\end{array}$ & $\begin{array}{l}\text { Offering ONLY medically } \\
\text { reasonable options } \\
\text { Narrative approach }\end{array}$ & $\begin{array}{l}\text { Imagination } \\
\text { Willingness to accept } \\
\text { decisional burden }\end{array}$ \\
\hline Session 3 & Adverse events & Shame versus guilt & Resiliency practices & Courage \\
\hline Session 4 & & $\begin{array}{l}\text { Apologies decrease likelihood } \\
\text { of lawsuits } \\
\text { NC "I'm sorry" statute }\end{array}$ & & $\begin{array}{l}\text { Compassion for self and others } \\
\text { Humility } \\
\text { Forgiveness }\end{array}$ \\
\hline Session 5 & End of life & Surrogacy in NC & SPIKES protocol & Self awareness \\
\hline Session 6 & & $\begin{array}{l}\text { DNR in OR } \\
\text { DCD and brain death }\end{array}$ & $\begin{array}{l}\text { Surprise question } \\
\text { MOST form }\end{array}$ & $\begin{array}{l}\text { Mindful presence } \\
\text { Therapeutic silence }\end{array}$ \\
\hline
\end{tabular}

DCD, donation after cardiac death; DNR, do not resuscitate; MOST, Medical Order for Scope of Treatment; NC, North Carolina; OR, operating room; SPIKES, Setting, Patient Perspective, Invitation, Knowledge, Emotions, Summary/Strategy.

that underlie some of their more challenging cases, and developing a framework with which to discuss or manage them, residents may experience more meaning in their work (Table 1).

\section{References}

1. American College of Graduate Medical Education: Common Program Requirements. American College of Graduate Medical Education. www .acgme.org/What-We-Do/Accreditation/Common-Program-Requirements. 2020. (Last accessed March 4, 2020).

2. Ferreres AR, Angelos P, Singer EA, et al. (eds). Ethical Issues in Surgical Care. Chicago, IL: American College of Surgeons, 2017.
Cite this article as: Forner $\mathrm{K}$ (2020) The credibility question: Challenge or opportunity?, Palliative Medicine Reports 1:1, 40-41, DOI: 10.1089/pmr.2020.0010.

\section{Publish in Palliative Medicine Reports}

$\mathrm{DCD}=$ donation after cardiac death

$\mathrm{DNR}=$ do not resuscitate

MOST $=$ Medical Order for Scope of Treatment

$\mathrm{NC}=$ North Carolina

$\mathrm{OR}=$ operating room

PGY $=$ post-graduate year

SPIKES = Setting, Patient Perspective, Invitation, Knowledge, Emotions, Summary/Strategy

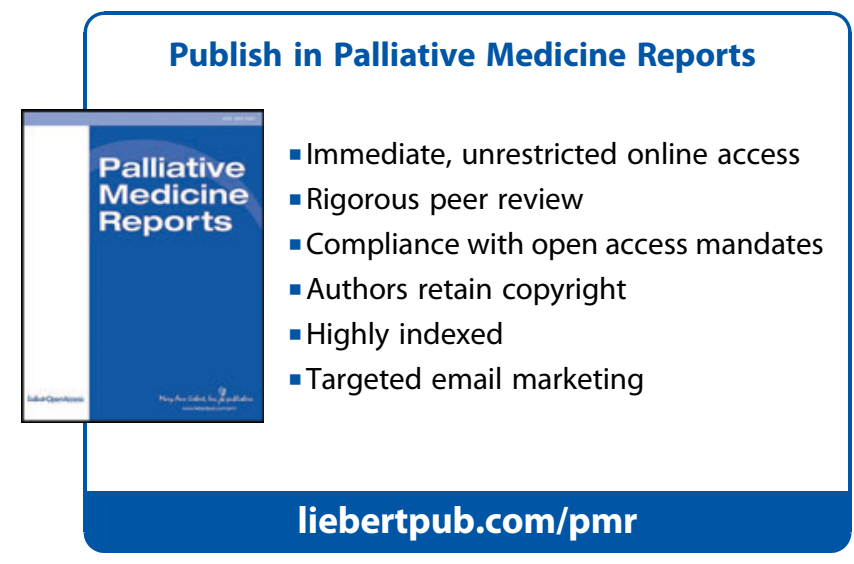

